\title{
Self-assembly in chemical systems
}

\author{
Steven J. Langford and J. Fraser Stoddart \\ School of Chemistry, University of Birmingham, Edgbaston, Birmingham B15 2TT, UK
}

\begin{abstract}
The development of a simple approach to studying self-assembly processes in the chemical laboratory began with an investigation of the donor/acceptor complexes formed between (a) crown ethers, like bisparaphenylene-34-crown-10, and 4,4'bipyridinium dications, such as paraquat, and (b) tetracationic cyclophanes, like cyclobis(paraquat-p-phenylene), and neutral substrates, such as 1,4dimethoxybenzene. Numerous template-directed syntheses that rely upon the post-assembly modification of the precursors, which lead to the tetracationic cyclophanes with their $\pi$-electron deficient components in the presence of macrocyclic or acyclic polyethers containing $\pi$-electron rich components, have afforded a wide range of catenanes and rotaxanes in recent years. By modifying the nature of the molecular recognition components, both sterically and electronically, it is possible to control the efficiency of the self-assembly process and also the proportions of the isomeric compounds present at equilibrium. This article gives a brief overview of some of the key molecular assemblies that have been constructed, as a result of an empirically-driven research programme, around interlocked molecules in which the components have been carefully selected to interact strongly and selectively with each other.
\end{abstract}

\section{PREAMBLE}

Throughout nature, complex molecular assemblies and supramolecular arrays are constructed from small and relatively simple building blocks through the utilization of three distinct processes - namely, those of selfassembly (ref. 1), self-organization (ref. 2), and self-replication (ref. 3). These three processes all require noncovalent bonding complementarity - usually between hydrogen bond donors and acceptors, but also between $\pi$-donors and $\pi$-acceptors, as well as recognition events involving electrostatic, dipole-dipole interactions, and metal-ligand interactions, to mention but another three sources only of structural and superstructural stabilization - built into their molecular components or supramolecular subunits. In biological systems, the best fits between substrates and receptors are found when there is good electronic, as well as an excellent steric match, in place. Indeed, the more rigid and preorganized a substrate and receptor are with respect to one another stereoelectronically, the stronger will be the complexation between them.

In the chemical laboratory, the term self-assembly relates to the use of these noncovalent bonding interactions mentioned already - sometimes augmented by the formation of reversible covalent bonds - to construct well-defined molecular assemblies and supramolecular arrays with a high degree of efficiency, selectivity, and control. This article deals with self-assembling systems that have resulted recently from a foray into the realm of the so-called (ref. 4) catenanes and rotaxanes (Fig. 1).

\section{A [2]Catenane}

Two Macrocyclic Interlocked Rings
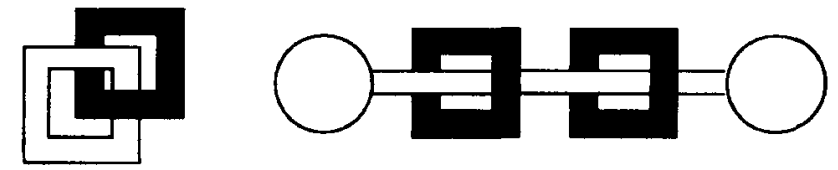

[3]Rotaxane

Two Macrocyclic Rings threaded on a Dumbbell

Fig. 1. A schematic representation of a [2]catenane and a [3]rotaxane

Catenanes are comprised of two or more interlocked macrocyclic components, which are held together at a molecular level mechanically, rather than by conventional (covalent) bonding. The components of the rotaxanes are also mechanically interlocked in such a way that the macrocyclic component(s) is/are threaded around a dumbbell component in which a "rod" is terminated by two large "stoppers," thus preventing the loss of the macrocycle(s) from the dumbbell component. Such molecules have long been chemical curiosities, particularly since their syntheses in the past by statistical methods has resulted (ref. 5) in modest amounts (typically $<1 \%$ ) of products being formed. 


\section{EVOLVING THE STRATEGY}

The discovery (ref. 6) that macrocyclic polyethers, such as dibenzo-30-crown-10 (DB30C10) and its constitutional isomer bisparaphenylene-34-crown-10 (BPP34C10) 1, form weak inclusion complexes $\left(K_{\mathrm{a}}\right.$ values of $c a .10^{3} \mathrm{M}^{-1}$ ) with diquat and paraquat $2.2 \mathrm{PF}_{6}$, respectively, in acetone was the starting point for a new line of research. In each case, the two components are ideally matched in the stereoelectronic sense. In BPP34C10, the central oxygen atoms in the polyether chains are perfectly positioned for hydrogen bonding to two of the $\mathrm{CH}$-acidic protons alpha to the nitrogen atoms of the paraquat dication $2^{2+}$. The centrosymmetric location of this dication within the BPP34C10 macrocycle allows (ref. 7) for an optimization of the dispersive forces, such as $\pi-\pi$ stacking and charge transfer interactions, between the $\pi$-electron rich dialkoxybenzene rings (separated by $6.8 \AA$ ) in 1 and the $\pi$-electron deficient bipyridinium units in $2^{2+}$, adding further to the stabilization of the $1: 1$ complex.
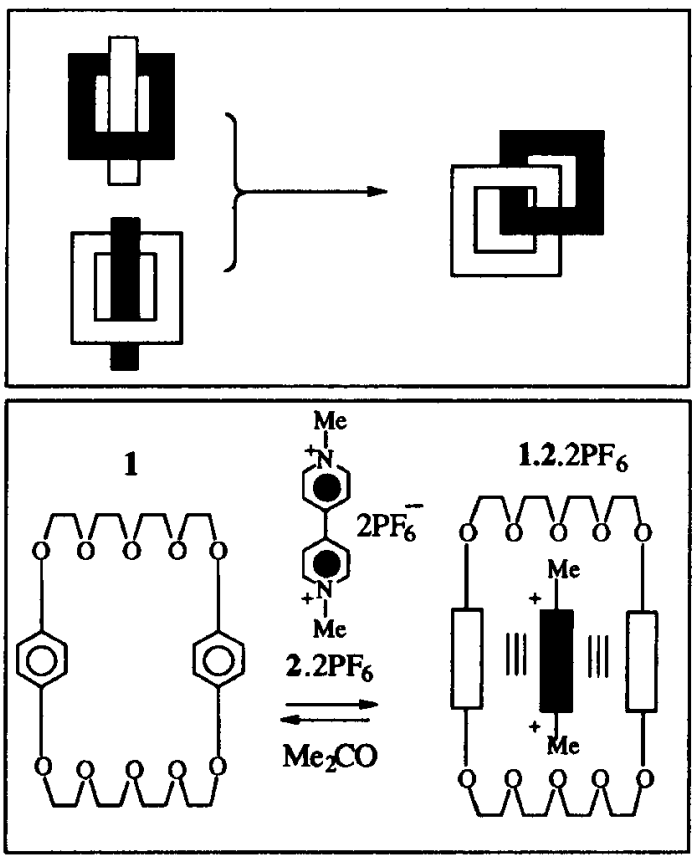

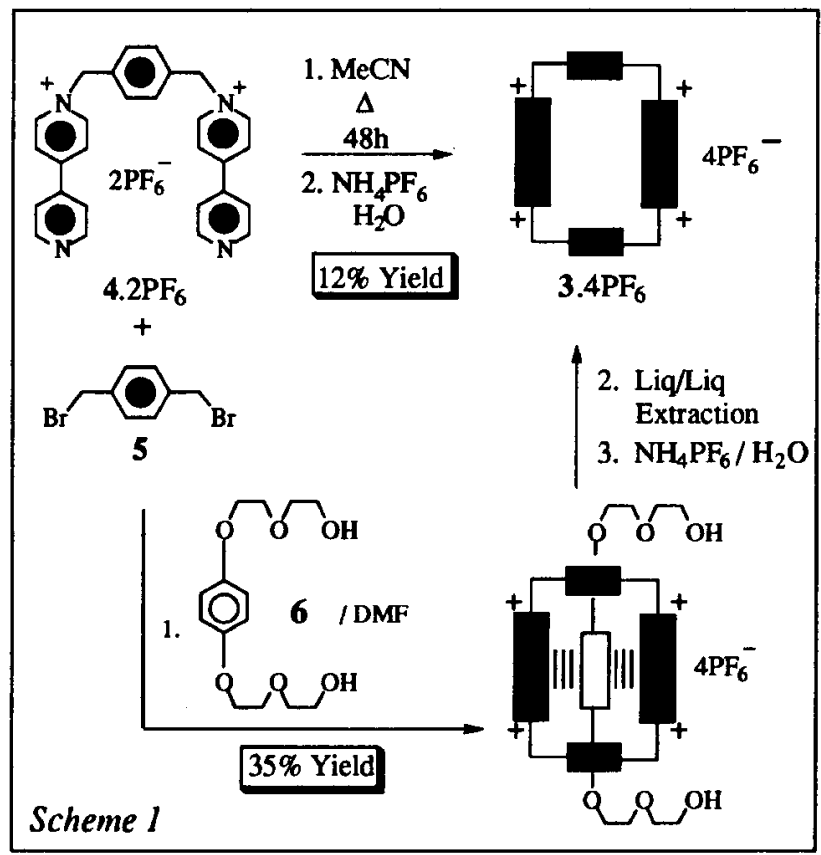

The next challenge was to devise the synthesis of a tetracationic cyclophane containing two $\pi$-electron deficient bipyridinium units that would bind with $\pi$-electron rich aromatic substrates. Following some molecular modelling - an exercise which revealed that two para-xylyl spacers will hold two bipyridinium units ca. $7 \AA$ apart - the immediate synthetic target became cyclobis(paraquat-p-phenylene) $3.4 \mathrm{PF}_{6}$. The development of an efficient route to the synthesis of $3.4 \mathrm{PF}_{6}$ unfolded in the following stepwise manner. Initially, the tetracationic cyclophane was formed (ref. 8) in acetonitrile under reflux at high dilution (Scheme 1) in the rather modest yield of $12 \%$ from $4.2 \mathrm{PF}_{6}$ and 1,4-bis(bromomethyl)benzene (5). Complexation between $3.4 \mathrm{PF}_{6}$ and derivatives, e.g. 6, of hydroquinone is an efficient process $\left(K_{\mathrm{a}}\right.$ values of $>2000 \mathrm{M}^{-1}$ in acetonitrile). It transpires that the tetracationic cyclophane $3.4 \mathrm{PF}_{6}$ has just the right size and shape for it to form a 1:1 complex with 6 in which the $\pi$ - $\pi$ stacking of the $\pi$-donor with the $\pi$-acceptors is augmented by [C-H...O] hydrogen bonding between the primary hydroxyl groups in 6 and two of the CHacidic protons alpha to the nitrogen atoms in $3^{4+}$, and edge-to-face interactions involving the hydroquinone ring in 6 and the $p$-xylyl spacers in $3^{4+}$. Next, we demonstrated that the acyclic polyether 6 with its hydroquinone ring can be used to template the synthesis of the tetracationic cyclophane $3.4 \mathrm{PF}_{6}$. The result was (ref. 7) at least a four-fold increase in the yield of $3.4 \mathrm{PF}_{6}$ under ambient pressure conditions and a fivefold increase when an ultrahigh (12 kbars) pressure reaction vessel was employed. Clearly, templates such as 6 , organize the $\pi$-electron deficient tetracationic cyclophane around them and in so doing favour cyclization over polymerization when $4.2 \mathrm{PF}_{6}$ is reacted with the dibromde 5 . We will now discuss how the templatedirected approach can become the basis for the efficient synthesis of catenanes and rotaxanes that rely principally on the three types of noncovalent bonding interactions we have already identified in this section. 


\section{MAKING CATENANES TO ORDER}

The first [2]catenane 7.4PF $\mathrm{PF}_{6}$ that was made (ref. 9) was self-assembled (Scheme 2) at room temperature in acetonitrile from $4.2 \mathrm{PF}_{6}, \mathrm{BPP} 34 \mathrm{Cl0}(1)$, and the dibromide 5 in the quite remarkable yield of $70 \%$ after counterion exchange! The threading of the crown ether component with its dual exolendo receptor character around the bipyridinium unit in the intermediate trication, formed after the first alkylation of $4.2 \mathrm{PF}_{6}$ with 5 , presumably directs the second alkylation so as to form the [2]catenane in preference to polycationic pseudorotaxanes. Since the late 1980s, we have rung the changes with respect to the nature of the $\pi$-electron deficient and rich residues, as well as in the aromatic spacer units and polyether chains in the two components of the [2]catenane $7.4 \mathrm{PF}_{6}$ in order to probe how selective are the noncovalent bonding interactions and to what extent the changes affect the yields in the molecular self-assembly processes.

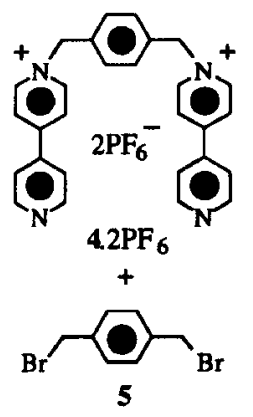

Scheme 2

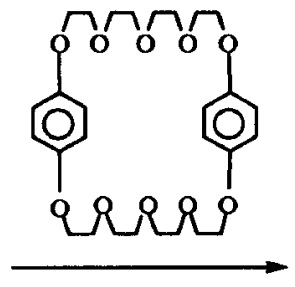

1. MeCN (or DMF) / RT

2. $\mathrm{NH}_{4} \mathrm{PF}_{6} / \mathrm{H}_{2} \mathrm{O}$

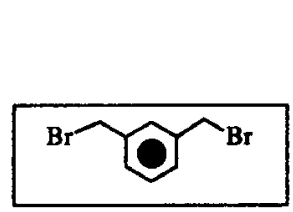

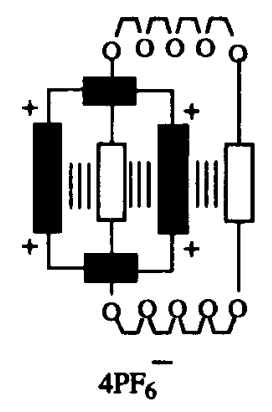

$*=7.4 \mathrm{PF}_{6}$

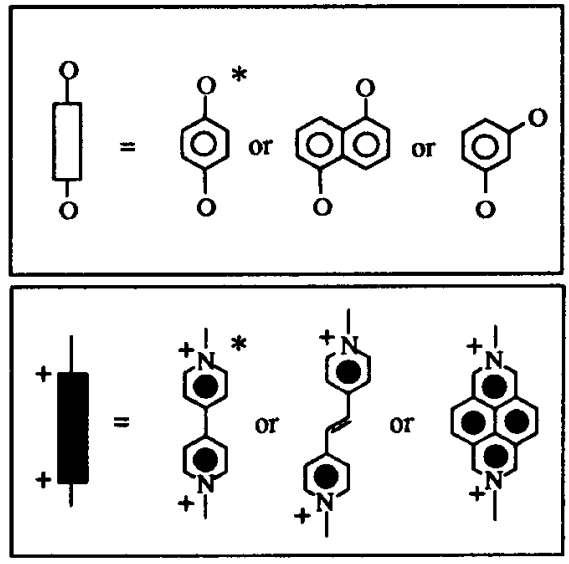

Some of the most interesting [2]catenanes to study from the dynamic point of view have been those which incorporate (i) two different types of shaded or unshaded units (ref. 10), or (ii) a combination of different shaded and unshaded units (as depicted in the keys in Scheme 2) in the tetracationic cyclophane and crown ether components, respectively. The dynamic motion of the rings in these [2]catenane is such that they have the ability, depending on the relevant activation barriers, to circumrotate through each other at rates that are usually significantly different. (There is also a very fast process that involves a rocking motion of one ring with respect to the other.) These activation barriers are dependent on the magnitudes of the noncovalent bonding interactions involving both sets of recognition sites within each of the two ring components as well as on steric factors. Hence, changing one of the recognition sites within one of the ring components could influence these motions in such a way as to create a bias at equilibrium towards one particular isomeric species - call it a translational isomer (ref. 11) of the [2]catenane in question. The two or more translational isomers differ on account of (i) which recognition sites occupy cavities inside the matching components, and (ii) which recognition sites take up positions alongside the other ring components. In respect to translational isomerism, the kinetic aspects (i.e. the rate of circumrotation of one ring through the other), as well as the thermodynamic aspects (i.e. the ratio of translational isomers present at equilibrium) are important and have to be understood at a fundamental level. The results of experiments carried out to date can be generalized in the following statements. 1. The more $\pi$-electron deficient or rich a recognition site is over its counterpart within one of the ring components, the greater is the chance that the residue associated with a particular recognition site will be included inside the cavity of the other ring component. 2 . When the cavity in one of the ring components is reduced dramatically in size, then the consequence of the steric compressions to decrease the activation barriers to translational isomerism and also to lower the efficiencies of the selfassembly processes leading to the [2]catenanes in the first place, e.g. introducing first one then two metaxylyl spacer units instead of a para-xylyl ones into the tetracationic cyclophane component reduces the yields obtained in the self-assembly of the [2]catenanes.

The success we experienced in linking two rings together to make [2]catenanes has aroused our curiosity towards the possibility of making chain-like molecules, i.e. [n]catenanes or polycatenanes. They constitute interesting compounds since their molecular architectures resemble mechanical chains wherein alternating macrocyclic polyethers and tetracationic cyclophanes give rise to a linked combination. It was immediately obvious that, if we were to make the progression from [2]catenanes to polycatenanes, then we would have to 
increase the size of both the macrocyclic polyether and tetracationic cyclophane components in order to allow two rings to thread themselves simultaneously through the cavities of both these components. The key step towards self-assembling polycatenanes (ref. 12) began with the template-directed synthesis of the [3]catenane 8.4PF 6 which includes two crown-15 ethers 9, containing three 1,5-dioxynaphthalene ring systems, and the larger tetracationic cyclophane $10.4 \mathrm{PF}_{6}$ in which $4,4^{\prime}$-bitolyl spacers have replaced the paraxylyl ones present in 3.4 PF $_{6}$.

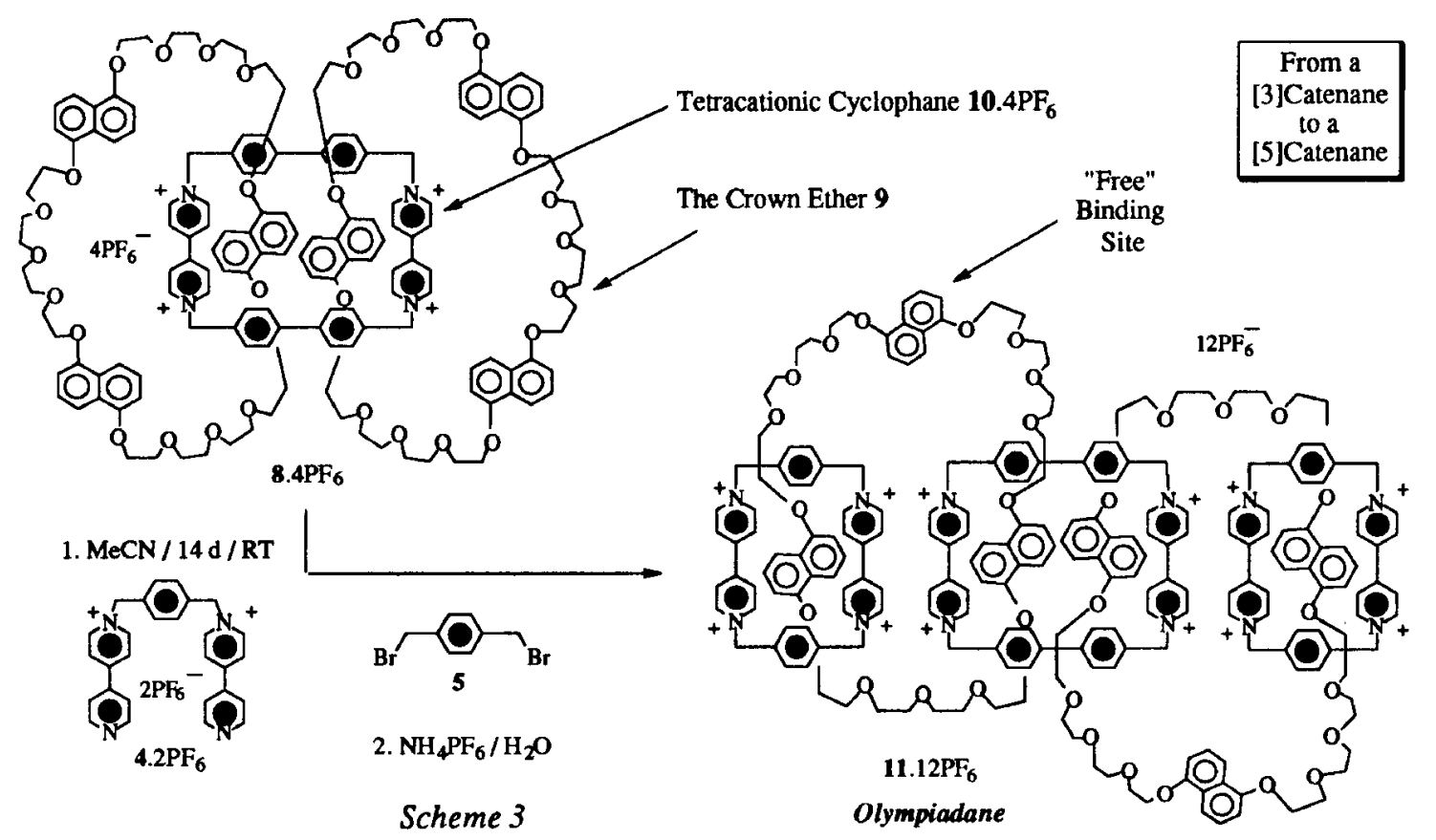

The four "free" recognition sites on the macrocyclic polyether components of the [3]catenane 8.4PF means $_{6}$ that this molecular assembly has the potential to be elaborated up to as far as a branched [7]catenane. (Attempts at similar elaborations in which the crown ether was trisparaphenylene-51-crown-15 led (ref. 13) to a [4]catenane and only traces of the expected linear [5]catenane: they were much more successful when the hydroquinone rings in the crown ether were replaced by 1,5-dioxynaphthalene ring systems.) Starting with the [3]catenane, reaction (Scheme 3) of $4.2 \mathrm{PF}_{6}$, with 5 in its presence afforded the [5]catenane 11.12 $\mathrm{PF}_{6}$ in 5\% yield. Because of the close analogy between its molecular structure and that of the symbol associated with the international Olympics movement, this compound has been given the trivial name, "Olympiadane" (ref. 12). Attempts to prepare the free tetracationic cyclophane $10.4 \mathrm{PF}_{6}$, which contains $4,4^{\prime}$-bitolyl spacers, have only recently been rewarded (ref. 14) with reasonable yields (10-32\%) as a result of template-directed procedures that rely on ferrocene and its derivatives fulfilling the role of templates.

One of the objectives in our research laboratory is to improve upon the efficiency of the self-assembly processes leading to higher catenanes and eventually to polycatenanes. Our present approaches (Fig. 2) include (a) the conventional chain one (as in Scheme 3), (b) the "bicycle-chain" one, and (c) the "anchorchain" one. A number of bis[2]catenanes (ref. 15, 16) have now been self-assembled with a view to them serving as model compounds for the "bicycle-chain" and "anchor-chain" approaches.

(a)

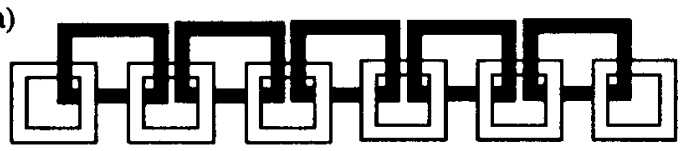

(b)

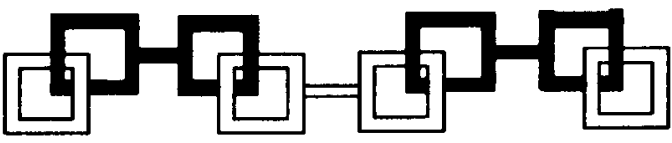

(c)

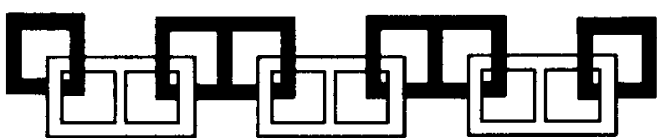

Fig. 2. Some of the pathways being pursued towards polycatenanes 


\section{ROTAXANES TO ORDER}

Rotaxanes are open to just as much structural variation and exploitation of translational isomerism as are the catenanes. The fact that it is possible to incorporate (ref. 7) both $\pi$-electron rich (ref. 17) and $\pi$-electron deficient (ref. 18) recognition sites into their dumbbell components means that we can explore the same aspects relating to the efficiencies of the self-assembly processes as well as produce molecular structures which exhibit translational isomerism.

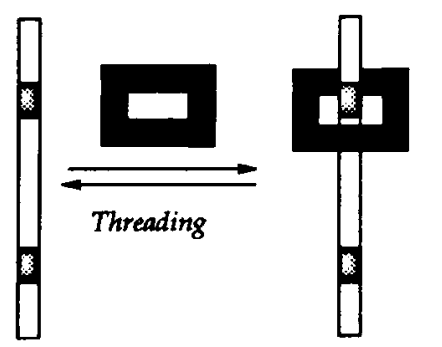

Scheme 4
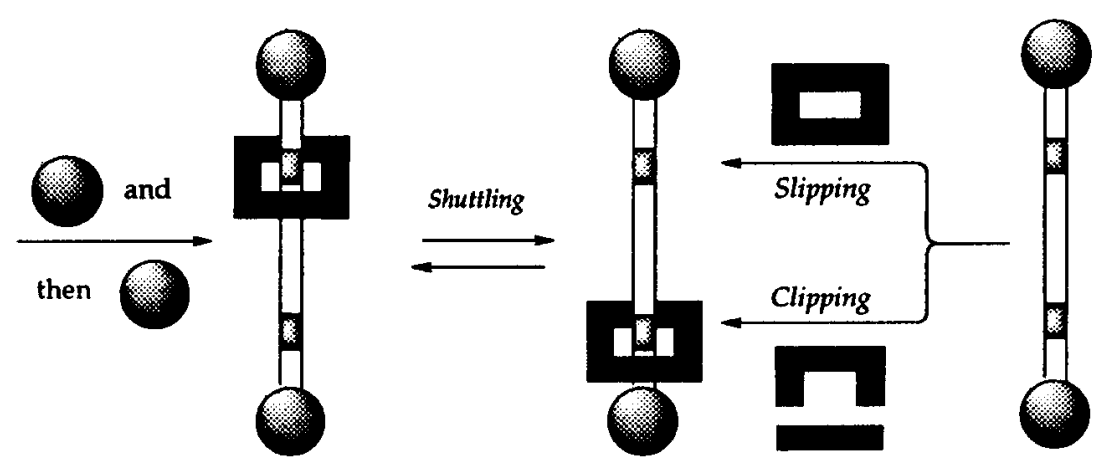

A major goal has been to try and control this isomerism in order to create nanoscale devices by influencing, either chemically, photochemically, or electrochemically, the interactions between the ring and the dumbbell components through the use of external stimuli such as protons, photons, and electrons, respectively. We aim to utilize the three self-assembly processes we have developed (ref. 7,18 ) - namely clipping, threading and slipping (Scheme 4) - to provide easy entries into nanometer-scale molecular architectures with machine-like properties to them. This possibility stems from the ability of the ring components in rotaxanes to "shuttle" back and forth along their dumbbell components. When different recognition sites are present in the dumbbell components, then it is possible to control the shuttling process so that one of the translational isomers is favored over the others. In one particular example (Scheme 5), it has been possible to control a molecular shuttle both chemically and electrochemically. Control is achieveable (ref. 19) by (i) protonation or (ii) oxidation of the benzidine station, which at $229 \mathrm{~K}$, is populated by the tetracationic cyclophane in 84\%. This stimulus either (i) causes a charge repulsion between the protonated nitrogens of the benzidine unit and the cyclophane, or (ii) by disrupting some of the dispersive interactions between the two units as well as a charge repulsion factor, causes the bead to move to the biphenol station. Reversibility is achieved by (i) the addition of a mild base, such as pyridine, or (ii) reduction of the radical cation - each method giving rise to the initial population of isomers.

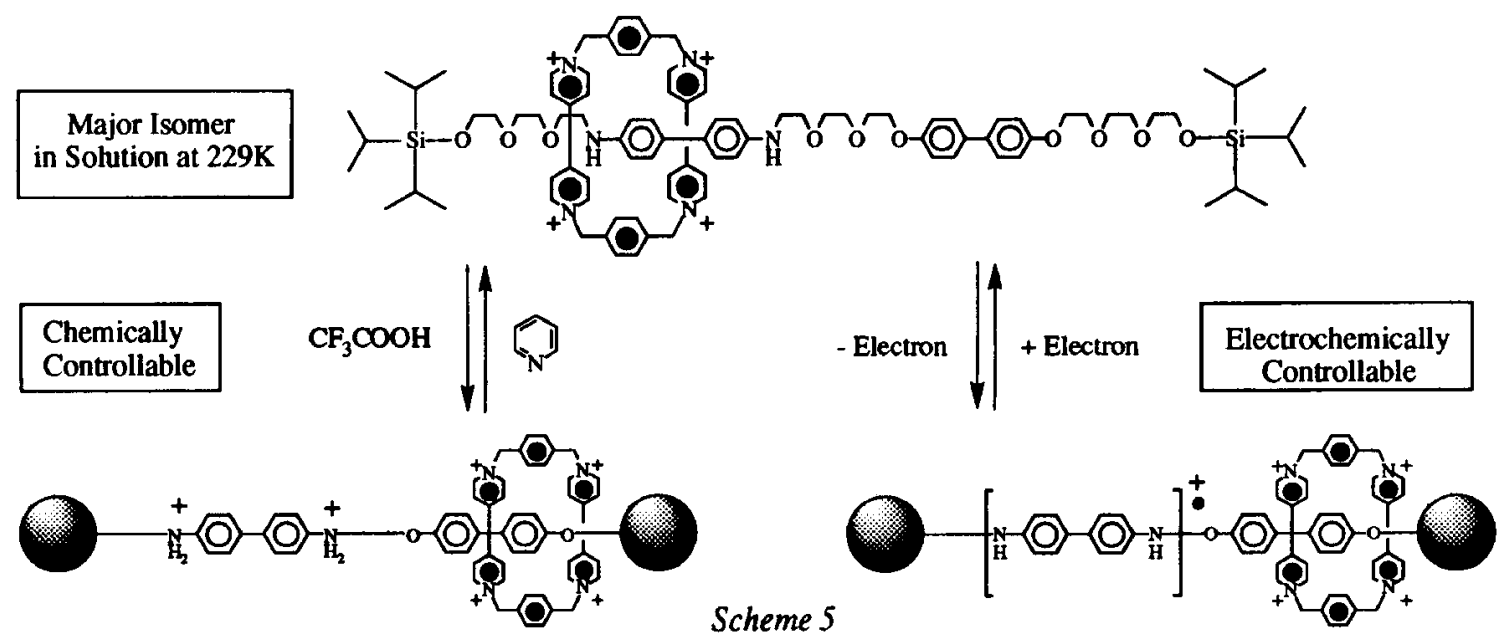

There is also a rapidly growing need that relates to the self-assembly of polyrotaxanes (ref. 20). Towards this goal, we have found (ref. 21) that, under the right conditions, up to a [4]rotaxane can be self-assembled efficiently by a procedure which involves slipping of the ring components over the stoppers of the dumbbell components under the influence of a little thermal energy. This protocol has been employed recently in the self-assembly of up to [4]rotaxanes of both a linear (ref. 21) and a branched (ref. 22) nature. 


\section{REFLECTIONS}

We have demonstrated that it is possible to use self-assembly processes to construct complex molecular assemblies with a high degree of control and precision from molecular components comprised of simple and inexpensive building blocks. The molecular components are encoded in such a way that they hold all of the information that is necessary for the construction of the selectively assembled structures and superstructures without the need for external reagents or catalysts. It is emerging that self-assembly occurs under very precise constitutional and - most likely - stereochemical control. Now, we are in the process of "fine tuning" the appropriate molecular components for the template-directed syntheses of a range of electrochemicallyactive and photochemically-responsive catenanes and rotaxanes in order to progress further towards building molecular devices as well as ultimately controlling the construction and the form of these mechanicallyinterlocked molecules with a view to self-assembling chain-like molecules with large molecular weights.

Acknowledgements. We wish to acknowledge financial support for this research from the EPSRC in the United Kingdom - and the Ramsay Memorial Trust for providing one of the authors (SJL) with a Ramsay Memorial Postdoctoral Fellowship.

\section{REFERENCES}

1. J.S. Lindsey New J. Chem. 15, 153-180 (1991).

2. W. Muller, H. Ringsdorf, E. Rump, G. Wildburg, X. Zhang, L. Angermaier, W. Knoll, M. Liley, and J. Spinke Science 262, 1706-1708 (1993).

3. (a) J. Rebek Jr. Chem. Br. 30, 286-290 (1994). (b) T. Li and K.C. Nicolaou Nature 396, 218-221 (1994).

(c) D. Sievers and G. von Kiedrowski Nature 369, 221-224 (1994). (d) F.M. Menger, A.V. Eliseev and N.A. Khanjin J. Am. Chem. Soc. 116, 3613-3614 (1994).

4. (a) G. Schill, Catenanes, Rotaxanes and Knots, Academic Press, New York (1971). (b) D. Philp, and J.F. Stoddart Synlett 445-458 (1991).

5. (a) E. Wasserman J. Am. Chem. Soc. 82, 4433-4434 (1960). (b) H.L. Frisch and E. Wasserman J. Am. Chem. Soc. 83, 3789-3795 (1961).

6. (a) H.M. Colquhoun, E.P. Goodings, J.M. Maud, J.F. Stoddart, J.B. Wolstenholme and D.J. Williams J. Chem. Soc.. Perkin Trans. Il 607-624 (1985). (b) B.L. Allwood, N. Spencer, H. Shahriari-Zavareh, J.F. Stoddart and D.J. Williams J. Chem. Soc., Chem. Commun. 1064-1066 (1987).

7. P.L. Anelli, P.R. Ashton, R. Ballardini, V. Balzani, M. Delgado, M.T. Gandolfi, T.T. Goodnow, A.E. Kaifer, D. Philp, M. Pietraszkiewicz, L. Prodi, M.V. Reddington, A.M.Z. Slawin, N. Spencer, J.F. Stoddart, C. Vicent, and D.J. Williams J. Am. Chem. Soc. 114, 193-218 (1992).

8. C.L. Brown, D. Philp, and J.F. Stoddart Synlett 462-464 (1991).

9. P.R. Ashton, T.T. Goodnow, A.E. Kaifer, M.V. Reddington, A.M.Z. Slawin, N. Spencer, J.F. Stoddart, C. Vicent, and D.J. Williams Angew. Chem., Int. Ed. Engl. 28, 1396-1399 (1989).

10. (a) P.R. Ashton, M. Blower, D. Philp, N. Spencer, J.F. Stoddart, M.S. Tolley, R. Ballardini, M. Ciano, V. Balzani, M.T. Gandolfi, L. Prodi, and C.H. McLean J. New. Chem. 17, 689-695 (1993). (b) P.R. Ashton, R. Ballardini, V. Balzani, M.T. Gandolfi, D.J.-F. Marquis, L. Pérez-García, L. Prodi, J.F. Stoddart, and M. Venturi J. Chem. Soc., Chem. Commun. 177-180 (1994).

11. G. Schill, K. Rissler, and W. Vetter Angew. Chem. Int. Ed. Engl. 20, 187-189 (1981).

12. (a) D.B. Amabilino, P.R. Ashton, A.S. Reder, N. Spencer, and J.F. Stoddart Angew. Chem. Int. Ed. Engl. 33, 12861290 (1994). (b) D.B. Amabilino, P.R. Ashton. C.L. Brown, E. Cordòva, L.A. Godinez, T.T. Goodnow, A.E. Kaifer, S.P. Newton, M. Pietraszkiewicz, D. Philp, F.M. Raymo, A.S. Reder, M.T. Rutland, A.M.Z. Slawin, N. Spencer, J.F. Stoddart, and D.J. Williams J. Am. Chem. Soc. 117, 1271-1293 (1995).

13. D.B. Amabilino, P.R. Ashton, A.S. Reder, N. Spencer, and J.F. Stoddart Angew. Chem. Int. Ed. Engl. 33, 433-437 (1994).

14. P.R. Ashton, S. Menzer, F.M. Raymo, J.F. Stoddart, and D.J. Williams Angew. Chem. Int. Ed. Engl. Submitted for Publication.

15. P.R. Ashton, J.A. Preece, J.F. Stoddart, and M.S. Tolley Synlett 789-792 (1994).

16. P.R. Ashton, J. Huff, S. Menzer, I.W. Parsons, J.A. Preece, J.F. Stoddart, M.S. Tolley, A.J.P. White, and DJ. Williams Eur. J. Chem. Submitted for Publication.

17. (a) P.L. Anelli, N. Spencer, and J.F. Stoddar, J. Am. Chem. Soc. 113, 5131-5133 (1991). (b) P.R. Ashton, R.A. Bissell, N. Spencer, J.F. Stoddart, and M.S. Tolley Synlett. 914-918 and 923-926 (1992). (b) P.R. Ashton, R.A. Bissell, R. Gorski, D. Philp, N. Spencer, J.F. Stoddart, and M.S. Tolley Synlett. 919-922 (1992).

18. P.R. Ashton, M. Bĕlohradský, D. Philp, and J.F. Stoddart J. Chem. Soc., Chem. Commun., 1269-1274 (1993).

19. R.A. Bissell, E. Cordòva, A.E. Kaifer, and J.F. Stoddart Nature 369, 133-137 (1994).

20. X. Sun, D.B. Amabilino, I.W. Parsons, and J.F. Stoddart Polymer Reprints, 34, 104-105 (1993).

21. P.R. Ashton, M. Bĕlohradský, D. Philp, and J.F. Stoddart J. Chem. Soc., Chem. Commun., 1274-1277 (1993).

22. D.B. Amabilino, P.R. Ashton, M. Bělohradský, F. Raymo, and J.F. Stoddart J. Chem. Soc., Chem. Commun. 751-753 (1995). 